\title{
Fuzzy Logic Controller for Speed and Torque in AC Servo System
}

\author{
L. Rodrigo Silva Sánchez, Antonio Hernández Zavala, \\ Jorge A. Huerta Ruelas \\ Centro de Investigación en Ciencia Aplicada y Tecnología Avanzada del \\ Instituto Politécnico Nacional (CICATA-IPN-QRO), Querétaro, \\ Mexico \\ lrodrigo.silva.s@gmail.com, anhernandezz@ipn.mx, jhuertar@ipn.mx
}

\begin{abstract}
This paper presents the application of a fuzzy-logic controller for an AC servomotor. The fuzzy-logic controller is coupled to conventional methods for AC Servo commutation, such as a field-oriented flux control and voltage amplifiers. A test bench platform was designed specifically to test the controller at different load values. The behaviour of the speed and torque variables got stable while maintaining the error deviation lower than 5\%, being a competitive option compared to the current literature.
\end{abstract}

Keywords: AC servomotor, fuzzy logic controller, speed control, torque control.

\section{Introduction}

Industrial automation is based in motion control of different mechanisms, for which induction motors and servomotors are used given its robustness and reliability. The controllers for motors and servomotors have become a key requirement for precise automation. The use of artificial intelligence in the fields of power electronics and speed control has increased significantly. These methods use fuzzy logic and artificial neural networks, which require little mathematical knowledge to describe the operation of the system, along with a logical instead of a mathematical analysis to control the system to facilitate decision-making.

This trend is accompanied of the electrical machine optimization for maximum performance, which involves the use of electronics that are more sensitive to disturbances, making necessary to implement compensation equipment taking into account factors that were previously not relevant. Fuzzy systems allow modelling a plant out of the knowledge of its functioning, and the controller realization is straightforward. Artificial neural networks need to have a learning stage, in which the user provides the input data and it shows which is the output or the expected response.

In many papers there is coupling between fuzzy and PID control techniques $[1,2$, 3]. For servomotor systems, it obtains better results than separately. The importance of 
this work is the implementation of fuzzy control to measure performance with the lowest number of membership functions in the three-phase inverter developed. Several papers have described how to couple the Fuzzy control to AC servo systems [1-15]. The controller responds according to the application of rules or algorithms that are related to the mechanism dynamics. Inferences are made according to the in line behaviour of the motor and its dynamic response [4, 5, 6, 7].

The application of artificial neural networks and fuzzy logic is based on the application of rules or algorithms that are not related to the mechanism, but to its behaviour. The advantages found were self-tuning, fast torque and flux response, without problems during low-speed operation $[8,9,10]$.

The work presented by Bor-Ren Lin [11], proposes a neural network for states interruptions voltage inverter using current control of hysteresis. In the case of L. Cabrera and Zinger [12], they present four training algorithms to emulate the sector stator in a DTC (Direct Torque Control).

The paper is organized as follows: Section 2 presents the electrical, mechanical and mathematical models of the servomotor in order to understand how it is controlled. Section 3 presents the design of the fuzzy logic controller for speed and torque. Section 4 shows the experiments realized along with the testing platform. The results are analysed and discussed in section 5, to finally present the conclusion.

\section{Model of the AC Servomotor}

Vectorial control began in the decade of the 70s in West Germany, with the principles stated in the work of Hass and Blaschke. The method focuses on the coupling and uncoupling of the magnetic flux of the motor, resulting in a dynamic behaviour similar to direct current motor. The simplified equations to obtain are convenient for the control system and for implementation. They can be written in the form of Ec. 1:

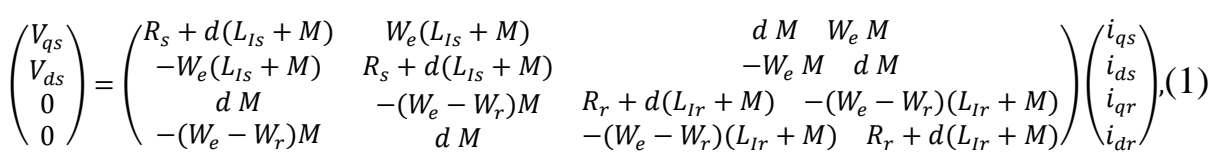

where

$d$ : differential operator,

$V_{q s}, V_{d s}$ : stator voltage of synchronously rotating $d^{e}-q^{e}$ reference frame,

$i_{q s}, i_{d s}$ : stator current of synchronously rotating $d^{e}-q^{e}$ reference frame,

$R_{r}, R_{s}$ : stator and rotor resistances, respectively,

$W_{e}, W_{r}$ : synchronous and rotor angular velocities, respectively,

where

$$
M=\frac{3}{2} L_{m s}
$$

$L_{m s}$ : the stator magnetizing inductance. 
The rotor speed and torque are related by the equation

$$
\frac{2}{p} J d\left(W_{r}\right)=T_{e}-T_{l},
$$

where

$p$ : Number of poles,

$J$ : the inertia of the rotor,

$T_{e}$ : electromagnetic torque,

$T_{l}$ : load torque.

The three-phase inverter topology was used. The circuit consists of three halfbridges, their respective phase input is formed by a DC power supply and an inductivecapacitive LC filter, as shown in Fig. 1.

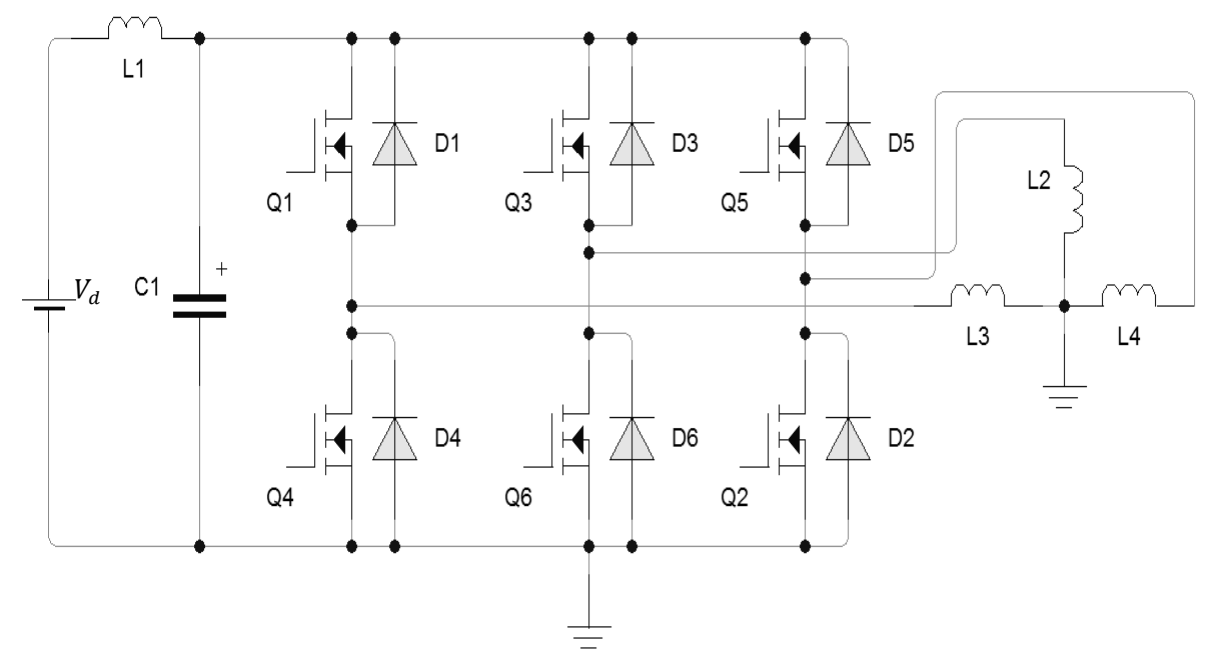

Fig. 1. Three-phase inverter (Half Bridge).

\section{$3 \quad$ Fuzzy Logic Controller}

The principal blocks that compose a fuzzy system are shown in Fig. 2. its operation requires first to convert one or more input data from a continuous universe (crisp) into fuzzy values in the fuzzification stage. Then, at the inference stage, it uses those fuzzy values to obtain a response out of the rule base which was previously filled with an expert knowledge to handle the system. Once a set of results is inferred, it is necessary to realize the inverse transformation, to convert the fuzzy value into a crisp value for modifying the system, the defuzzification stage. 


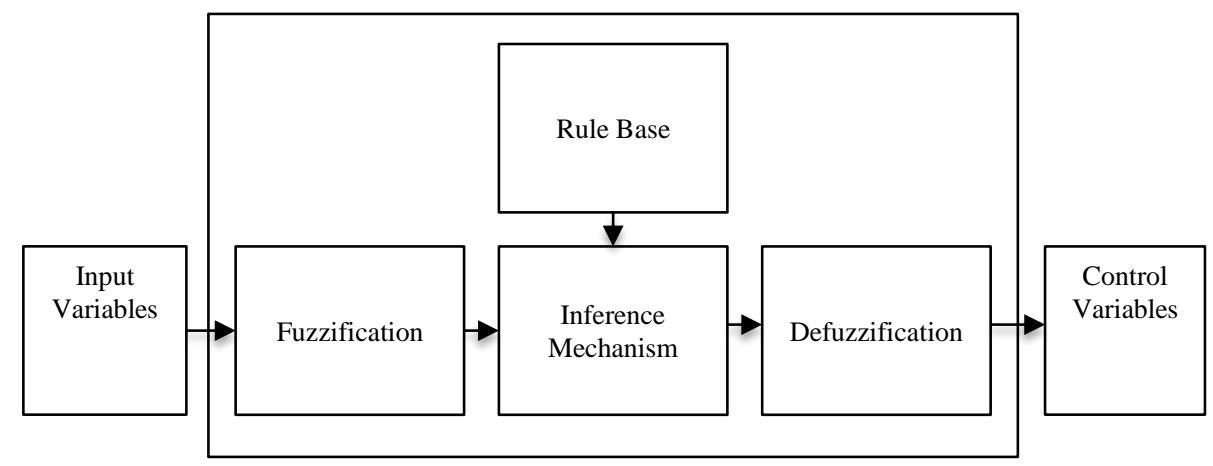

Fig. 2. General Block Diagram of Fuzzy System.

\subsection{Membership Function Definition}

The membership functions (MF) are proposed by the user. In this case, the definition of the membership functions was performed using three triangular membership functions for the input and output variables. Each MF is defined by the triangular MF general equation (4):

$$
\mu(x)=\left\{\begin{array}{c}
0, a<b \\
m x+b, b \leq c \\
-m x+b, c \leq d \\
0, d \leq e
\end{array}\right.
$$

For the case of the input variable error, the linguistic terms used to identify each MF are: Negative Small (NS), Zero (ZE), and Positive Small (PS), they are distributed graphically as shown in Fig. 3. The corresponding equations are (5)-(7). The same configuration was used for the output variable as in Fig. 4.

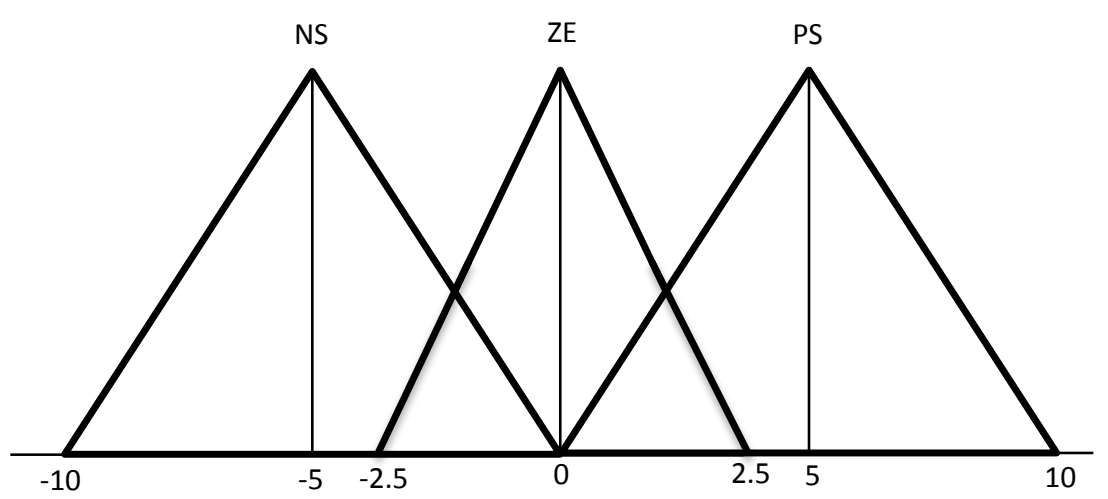

Fig. 3. The membership functions for error input. 


$$
\begin{gathered}
\mu_{N S}(x)=\left\{\begin{array}{c}
0,-\infty<-10 \\
0.2 x+2,-10 \leq-5 \\
-0.2 x+0,-5 \leq 0 \\
0,0 \leq \infty
\end{array}\right. \\
\mu_{Z E}(x)=\left\{\begin{array}{c}
0,-\infty<-2.5 \\
0.4 x+1,-2.5 \leq 0 \\
-0.4 x+1,0 \leq 2.5 \\
0,2.5 \leq \infty
\end{array}\right.
\end{gathered}
$$

$$
\mu_{P S}(x)=\left\{\begin{array}{c}
0,-\infty<0 \\
0.2 x+0,0 \leq 5 \\
-0.2 x+2,5 \leq 10 \\
0,10 \leq \infty
\end{array}\right.
$$

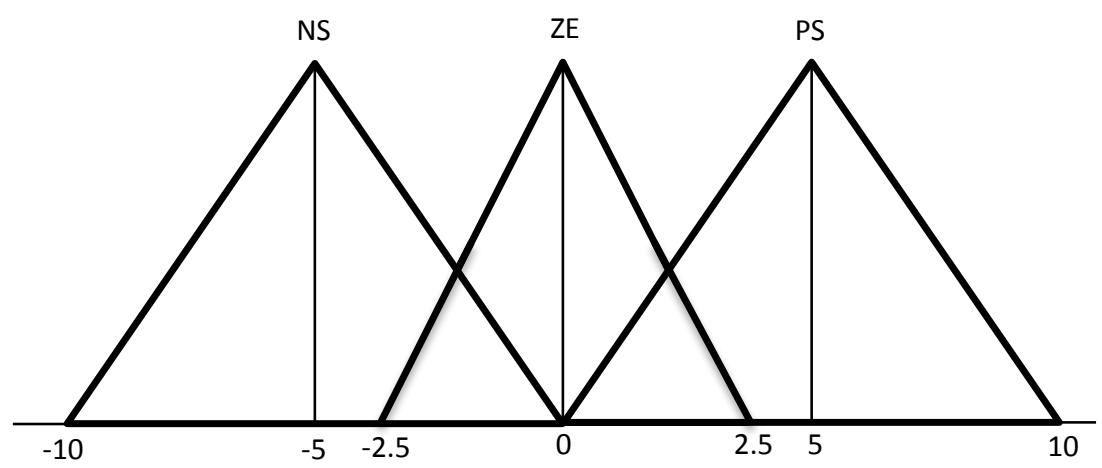

Fig. 4. Membership function for output.

\subsection{Inference Mechanism and Rule Base}

The inference mechanism is responsible for evaluating the fuzzy data membership values, obtained by the fuzzifier into the fired rules from the rule base. In this sense, the inference mechanism delivers the membership values, corresponding to the output membership functions. To generate the rule base, It is required a prior knowledge of an expert because without this it is very difficult generating a rule base applicable to process control.

Our controller uses the Mamdani model, which establishes rules defined by the following equation:

$$
R_{i}: \operatorname{IF} x=A_{i} \text { and } y=B_{i} \text { THEN } z=C_{i} \text {. }
$$

For example:

$$
\text { Rule }_{1} \text { : IF In is NP and Out is NP THEN } z \text { is PP. }
$$

The number of rules used in this controller is seven. Table 1 shows the rule base distribution used to describe the input and output variables relation. 
Table 1. Rule-Base.

\begin{tabular}{c|ccc}
\hline IN/OUT & NP & ZE & PP \\
\hline NP & PP & NP & X \\
ZE & NP & ZE & PP \\
PP & $\mathrm{X}$ & PP & NP \\
\hline
\end{tabular}

\subsection{Defuzzification}

Defuzzification stage is responsible for converting the fuzzy values obtained after the evaluation, into crisp values.

For this controller, the Mean of Maxima MOM defuzzifier is used. This defuzzifier, analyses the fuzzy values and determines the values in which $\mu_{B}(y)$ is a maximum. Subsequently, it calculates the average of these values as output if the maximum value of $\mu_{B}(y)$ occurs only once:

$$
y=\operatorname{MOM} \sum_{j=1}^{l} \frac{\mu\left(x_{j}\right)}{l}
$$

\section{$4 \quad$ Fuzzy Logic Controller}

The suggested speed control system was implemented for the AC servomotor coupled to a test bench. To implement the fuzzy controller we used an 8-bit microcontroller coupled to a synchronizer phase and a three-phase inverter, which were developed as in Fig. 5. Table 2 shows the characteristics of the servomotor that was used for testing.

Fig. 7 shows: a) the controller response for a 100-rpm set point, b) torque and c) Magnetic flux with a fixed preload of 1,156 N.m. All variables were taken simultaneously to verify control responses. The overshoot is too large at the beginning, and then it slowly declines until it stabilizes.

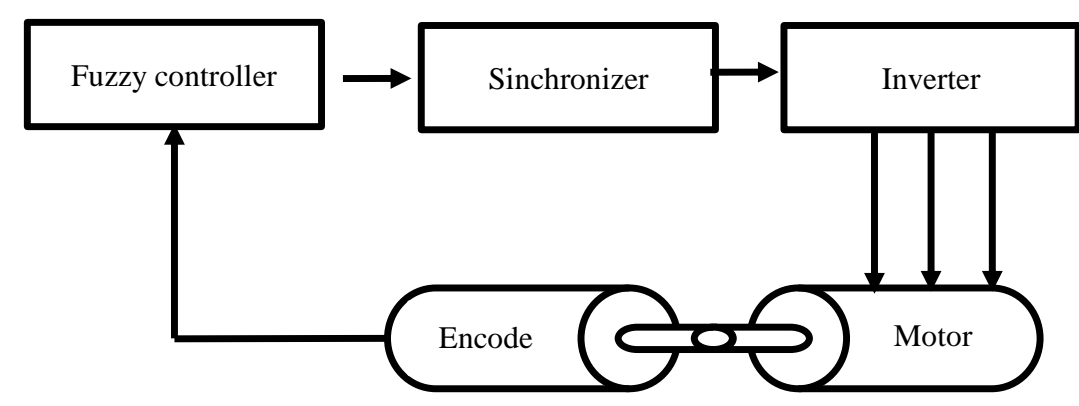

Fig. 5. Diagram of the implementation of fuzzy control. 
Fig. 6 shows the developed test bench and driver in which the torque and speed experiments were performed.

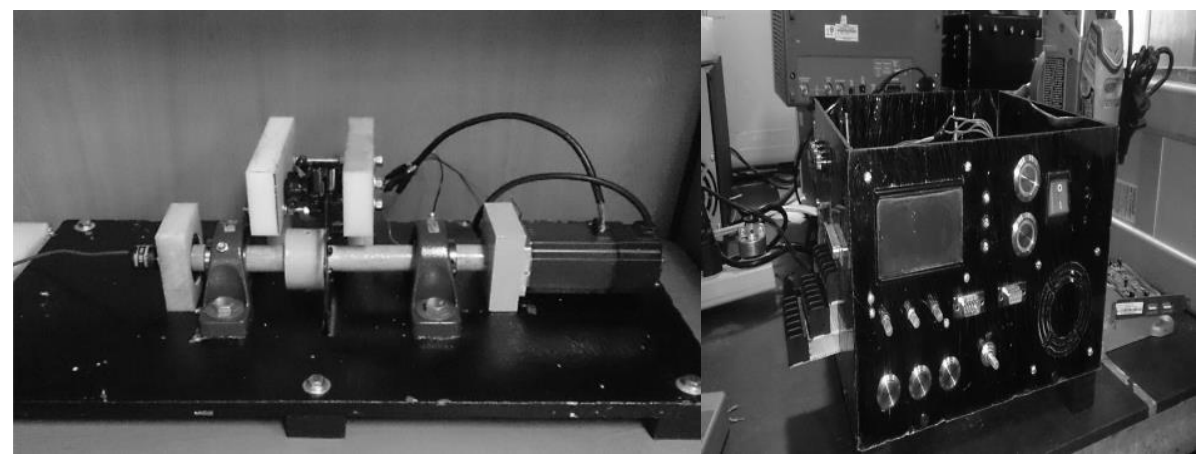

Fig. 6. Photograph of the AC Servomotor Test Bench and driver developed.

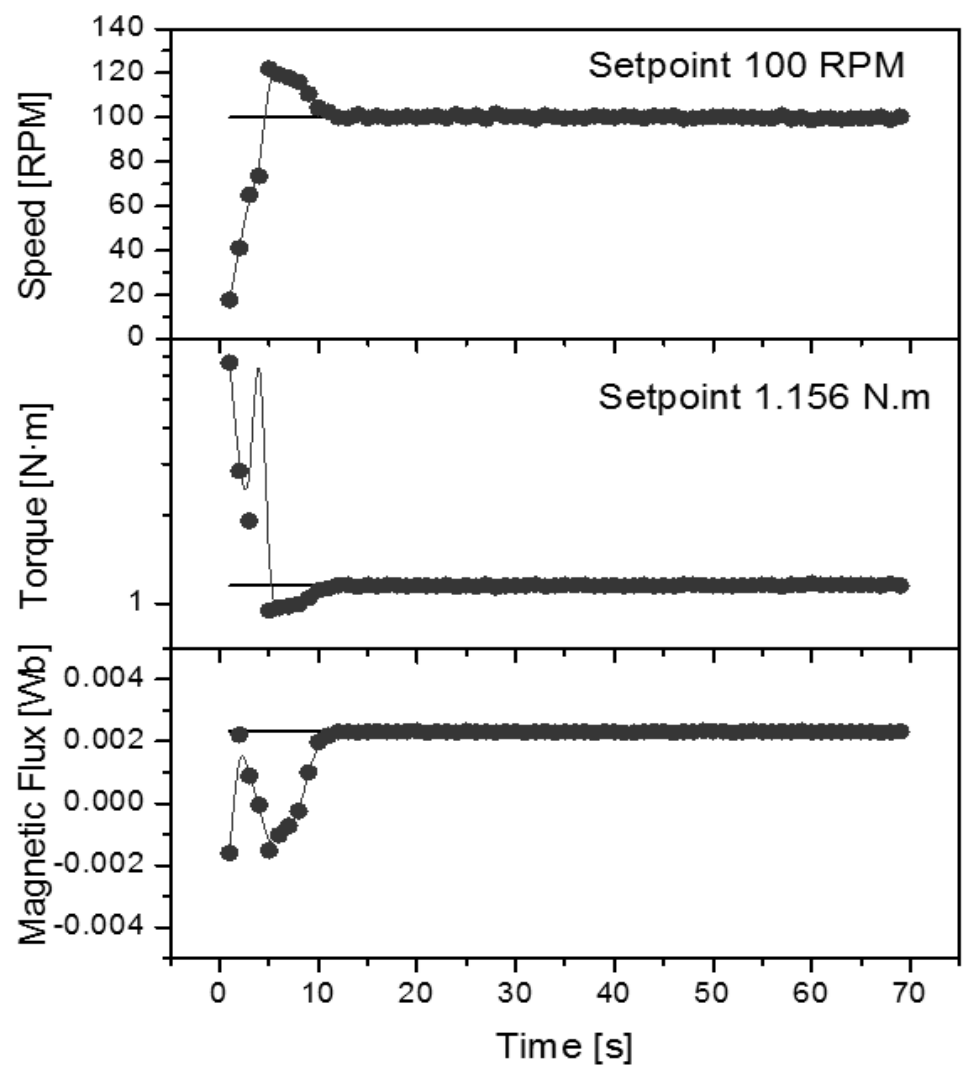

Fig. 7. Motor response tuned to a set point of 100 RPM's and a fixed preload of $1.156 \mathrm{Nm}$. a) the controller response b) torque and c) Magnetic flux. 
L. Rodrigo Silva Sánchez, Antonio Hernández Zavala, Jorge A. Huerta Ruelas

Table 2. Main data for AC servomotor used to test Fuzzy controller.

\begin{tabular}{lccc}
\hline \multicolumn{1}{c}{ Description } & Symbol & Quantity & Unit \\
\hline Stator voltage & $V_{d}$ & 220 & $\mathrm{~V}$ \\
\hline Rotor resistance & $R_{r}$ & 0.816 & $\mathbf{\Omega}$ \\
\hline Stator resistance & $R_{S}$ & 0.918 & $\mathbf{\Omega}$ \\
\hline Slip index & $\mathrm{S}$ & 0.16 & \\
\hline $\begin{array}{l}\text { The stator magnetizing } \\
\text { inductance }\end{array}$ & $L_{m s}$ & 1.311 & $\mathrm{H}$ \\
\hline The inertia of the rotor & $j$ & 0.0143 & $\mathrm{Kg} . \mathrm{m}^{2}$ \\
\hline
\end{tabular}

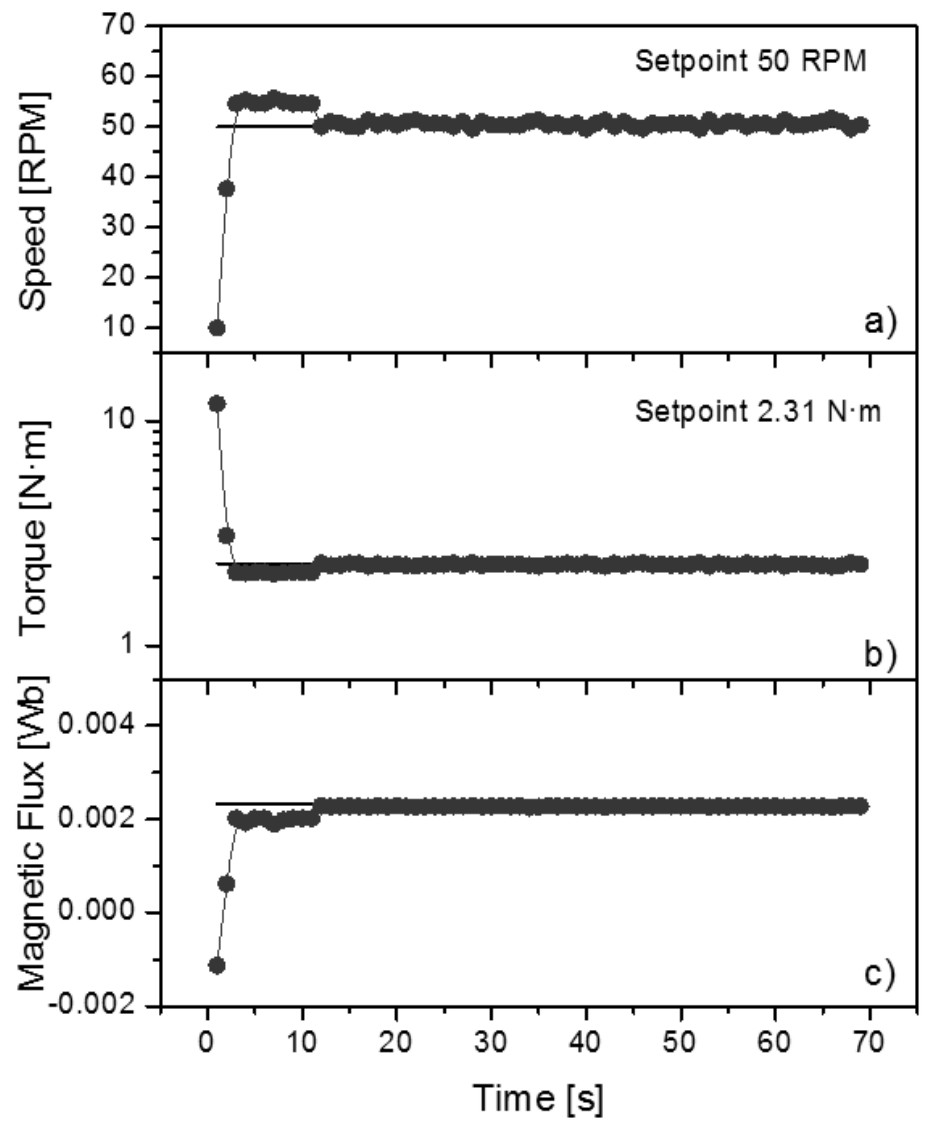

Fig. 8. Motor response tuned to a a set point of 50 RPM's and a fixed preload of $2.31 \mathrm{Nm}$. a) the controller response b) torque and c) Magnetic flux. 
Fig. 8 shows: a) the controller response for a 50-rpm set point, b) torque and c) Magnetic flux with a fixed preload of 2.31 N.m. All variables were taken simultaneously to verify control responses. The overshoot is too large at the beginning, and then it slowly declines until it stabilizes.

The nominal AC servomotor torque is $1.3 \mathrm{~N}$.m. therefore is difficult for the controller to stabilize in the $5 \%$ error range. It is seen that the magnetic flux is below that the set point, since the preload is greater than the nominal for this AC servomotor.

\section{Discussion}

From the results, it can be deduced that it is possible to couple the fuzzy control technique with vector control techniques.

It is seen that different tests have a similar behaviour, notorious from the responses of control graphs at different reference values $(50,100) \mathrm{rpm}$. The controller stabilizes effectively in the $5 \%$ range despite of the few membership functions used for the controller.

Table 3. Error comparison in FLC with vector techniques in AC Servomotor.

\begin{tabular}{|c|c|c|c|c|c|}
\hline Authors & $\begin{array}{l}\text { Control } \\
\text { technique in the } \\
\text { inverter }\end{array}$ & Control & $\begin{array}{c}\text { Variable to } \\
\text { Control }\end{array}$ & Test & $\begin{array}{c}\text { Error } \\
\text { (e) }\end{array}$ \\
\hline Silva et al. & FOC & Fuzzy & $\begin{array}{l}\text { Torque } \\
\text { Speed }\end{array}$ & Real & $\mathrm{e}<5 \%$ \\
\hline $\begin{array}{c}\text { Feng-Fu Chen } \\
{[13]}\end{array}$ & FOC & Fuzzy & $\begin{array}{c}\text { Torque } \\
\text { Speed } \\
\text { Position }\end{array}$ & $\begin{array}{l}\text { Simulation / } \\
\text { Real }\end{array}$ & $e<6 \%$ \\
\hline $\begin{array}{c}\text { Gilberto C. D. } \\
\text { [14] }\end{array}$ & FOC & Fuzzy & $\begin{array}{l}\text { Torque } \\
\text { Speed }\end{array}$ & Real & $e<6 \%$ \\
\hline $\begin{array}{c}\text { Pawel } \\
\text { Grabowski [9] }\end{array}$ & DTC & $\begin{array}{l}\text { Neuro } \\
\text { Fuzzy }\end{array}$ & Torque & Real & $e<7 \%$ \\
\hline $\begin{array}{c}\text { Faa-Jeng Lin } \\
{[10]}\end{array}$ & FOC & $\begin{array}{l}\text { Neuro } \\
\text { Fuzzy }\end{array}$ & $\begin{array}{c}\text { Torque speed } \\
\text { Position }\end{array}$ & Simulation & $e<7 \%$ \\
\hline $\begin{array}{c}\text { Giuseppe Buja } \\
{[15]}\end{array}$ & DTC & Fuzzy & Torque & Real & $\mathrm{e}<2 \%$ \\
\hline
\end{tabular}

It is important to notice that an increase in the number of membership functions used for input and output, will lead us to better results. Nevertheless, if we consider that we require an 8-bit microcontroller implementation, we cannot use many membership functions to define the fuzzy system, since it will consume much more memory and processing time. In this sense, we chose a basic implementation 
for our speed controller in order to maintain a reasonable response time and resource consumption.

It can be concluded that the steady state error remains between $3 \%$ and $5 \%$, which, if compared to commercial drivers is still high, since most of them handle $1 \%$ standard error. However, when compared with other paper works, they present a similar error as seen in Table 3. Another aspect observed in control graphs is that you can see a bigger overshoot, causing the generation of harmonics in the stator phases resulting in overheating.

\section{Conclusions}

The proposed controller was successfully implemented in the AC servomotor, by coupling techniques for vector control of induction motors and fuzzy logic. It was also achieved that the steady state error remains lower than $5 \%$ in tests at different speeds and preloads.

Compared to other drivers developed by researchers, the proposed controller is competitive, since it was implemented in an 8-bit microcontroller using the simplest structure in order to efficiently use the computational resources. Implementing neural networks coupled with fuzzy logic and vector control error would increase the response time due to large information processing.

Acknowledgments. Authors would like to thank CONACYT and the Instituto Politécnico Nacional (IPN), for their financial support.

\section{References}

1. Manikandan, R.: Design of Equivalent Fuzzy PID Controller From The Conventional PID Controller. Int Conf Control Commun Comput Technol, India, pp. 356-362 (2015)

2. Zhao, Z.Y., Tomizuka, M., Isaka, S.: Fuzzy gain scheduling of PID controllers. In: Proceedings First IEEE Conf Control Appl, pp. 698-703 (1992)

3. Choi, H.H., Yun, H.M., Kim, Y.: Implementation of Evolutionary Fuzzy PID Speed Controller for PM Synchronous Motor. IEEE Trans Ind Informatics, Vol. 11, pp. 540-547 (2015)

4. Kung, Y., Wang, M., Huang, C.: Digital Hardware Implementation of Adaptive Fuzzy Controller for AC Motor Drive. In: Ind Electron Soc 2007 IECON 2007 33rd Annu Conf IEEE, Taiwan, pp. 1208-1213 (2007)

5. Lubin, T., Mendes, E., Marchand, C.: Fuzzy Controller in A.C. Servo Motor Drive. In: Electrical Machine Drives, Seventh Int Conf (Conf Publ No 412), pp. 11-13 (1995)

6. Uddin, M.N., Rebeiro, R.S.: Fuzzy Logic Based Speed Controller and Adaptive Hysteresis Current Controller Based IPMSM Drive for Improved Dynamic Performance. pp. 1-6 (2011)

7. Suyitno, A., Strefezza, M., Dote, Y.: Variable - Structured Robust Control by Fuzzy Logic and Stability Analysis for AC Drive System. Singapore, pp. 51-56 (1993)

8. Dazhi, W., Guoqing, J., Jun, L.: A Novel Hysteresis Current Control Strategy Based on Neural Network. Vol. 2, pp. 369-372 (2010) 
9. Grabowski, P.Z., Member, A., Kazmierkowski, M.P.: A Simple Direct-Torque NeuroFuzzy Control of PWM-Inverter-Fed Induction Motor Drive. Vol. 47, pp.863-870 (2000)

10. Lin, F.J., Chiu, S.L.: Adaptive Fuzzy Sliding-Mode Control for PM Synchronous Servo Motor Drives. IEEE Proc Control Theory Appl., Vol. 145, pp. 63-72 (1998)

11. Lin, B.R., Hoft, R.G.: Power Electronics Inverter Control With Neural Networks. Appl Power Electron Conf Expo Eighth Ann, pp. 128-134 (1993)

12. Cabrera, L.A., Elbuluk, M.E., Zinger, D.S.: Learning Techniques to Train Neural Networks as a State Selector. In: Power Electron Spec Conf PESC'94 Rec 25th Annu IEEE, Vol. 12, pp. 233-242 (1994)

13. Cheng, F.F.: Application of Fuzzy Logic in the Speed Control of AC Servo System And an Intelligent Inverter. IEEE Trans Energy Convers, Vol. 8, pp. 312-318 (1993)

14. Sousa, G., Bose, B.K., Cleland, J.G.: Fuzzy logic based on-line efficiency optimization control of an indirect vector-controlled induction motor drive. IEEE Trans Ind Electron, Vol. 42, pp. 192-198 (1995)

15. Buja, G.S., Kazmierkowski, M.P.: Direct Torque Control of PWM Inverter-Fed AC Motors-A Survey. IEEE Trans Ind Electron, Vol. 51, pp. 744-757 (2004) 